\title{
Electrospun PHEA-PLA/PCL Scaffold for Vascular Regeneration: A Preliminary in Vivo Evaluation
}

\author{
S. Buscemi $i^{a, \star}$, V.D. Palumbo ${ }^{\mathrm{b}}$, A. Maffongelli ${ }^{\mathrm{b}}$, S. Fazzotta ${ }^{\mathrm{b}}$, F.S. Palumbo ${ }^{\mathrm{c}}$, M. Licciardi ${ }^{\mathrm{c}}$, C. Fiorica ${ }^{\mathrm{c}}$, \\ R. Puleio ${ }^{d}$, G. Cassata ${ }^{d}$, L. Fiorello ${ }^{a}$, G. Buscemi ${ }^{b, e}$, and A.I. lo Monte ${ }^{b, e}$

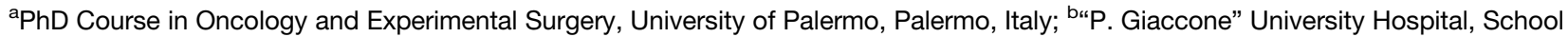 \\ of Medicine, University of Palermo, Palermo, Italy; 'Department of Biologic, Chemical, and Pharmaceutical Sciences and Technologies, \\ University of Palermo, Palermo, Italy; '“A. Mirri” Zooprophylactic Institute of Sicily, Palermo, Italy; and "Dichirons Department, University \\ of Palermo, Palermo, Italy
}

\begin{abstract}
Background. There is increasing interest in the development of vessel substitutes, and many studies are currently focusing on the development of biodegradable scaffolds capable of fostering vascular regeneration. We tested a new biocompatible and biodegradable material with mechanical properties similar to those of blood vessels.

Methods. The material used comprises a mixture of $\alpha, \beta$-poly $(N$-2-hydroxyethyl)D,L-aspartamide (PHEA) and polylactic acid (PLA), combined with polycaprolactone (PCL) by means of electrospinning technique. Low-molecular-weight heparin was also linked to the copolymer. A tubular PHEA-PLA/PCL sample was used to create an arteriovenous fistula in a pig model with the use of the external iliac vessels. The flow was assessed by means of Doppler ultrasound examination weekly, and 1 month after the implantation we removed the scaffold for histopathologic evaluation.

Results. The implants showed a perfect leak-proof seal and adequate elastic tension to blood pressure. About $\sim 3$ weeks after the implantation, Doppler examination revealed thrombosis of the graft, so we proceeded to its removal. Histologic examination showed chronic inflammation, with the presence of foreign body cells and marked neovascularization. The material had been largely absorbed, leaving some isolated spot residues.

Conclusions. The biocompatibility of PHEA-PLA/PCL and its physical properties make it suitable for the replacement of vessels. In the future, the possibility of functionalizing the material with a variety of molecules, to modulate the inflammatory and coagulative responses, will allow obtaining devices suitable for the replacement of native vessels.
\end{abstract}

$\mathbf{I}^{\mathbf{N}}$ clinical practice, there is a strong need for alternatives to the use of autologous vascular grafts for vascular reconstructive surgery (eg, coronary bypass, bypass of the lower limbs, arteriovenous fistulas) [1,2]. Currently, autologous vessels, especially the saphenous vein, are the most widely used materials for the replacement of small arterial vessels [1-3]. Immunologic compatibility is one of the biggest advantages of using these patches; however, sometimes we cannot use human autologous as vascular substitutes and we have to resort to an alternate patch. The biologic patches used are limited to some prostheses and are

$0041-1345 / 17$

http://dx.doi.org/10.1016/j.transproceed.2017.02.017
Funding: PRIN 2015: "Chirurgia rigenerativa nei difetti della parete addominale e nel deficit congenito o acquisito delle vie escretrici urinarie, biliari e dei vasi sanguigni: modellamento e crescita cellulare su scaffold planare e su scaffold tubulare. Studio sperimentale in vivo su modello suino" (2015X5AH3Z).

*Address correspondence to Salvatore Buscemi, University of Palermo, Via Del Vespro, 129, 90127 Palermo, Italy. E-mail: buscemi.salvatore@gmail.com

(c) 2017 Elsevier Inc. All rights reserved. 230 Park Avenue, New York, NY 10169 
often represented by autologous pericardium, allogeneic or xenogeneic (fixed in glutaraldehyde). Unfortunately, these patches have well known limitations: They are subject to greater risk of infections and thrombosis, they tend to calcify, and often they cause foreign body reactions and do not guarantee an adequate growth potential [4-10].

Vascular grafts made from synthetic materials, such as polyester and expanded polytetrafluoroethylene, are routinely used to restore the blood flow in patients with various cardiovascular disorders. They still have many disadvantages, such as thrombogenicity, intimal hyperplasia, stenosis and occlusion (especially in the small caliber grafts), susceptibility to infections, formation of pseudoaneurysms, and lack of growth potential [3,11-13]. Therefore, a completely bioabsorbable vascular patch, capable of inducing the regeneration of a new vessel wall, may overcome the limitations of the current artificial patches, serving as architectural support for the development of the neotissue. Tissue engineering is focusing on the development of biomaterials capable of mimicking the biologic and mechanical functions of the extracellular matrix (ECM). In fact, it has been shown that tissue morphogenesis is strongly influenced by interactions between cells and the ECM [14-26].

The present study aimed to test a new material as a bioabsorbable substitute for blood vessels in a pig model. This material initially should behave like the common vascular prosthesis and, at a later stage, once degraded and reabsorbed by the host organism, should replace the graft in a new blood vessel with anatomic and functional characteristics similar to those of native vascular vessels.

\section{METHODS}

The scaffold we tested was created in the Biocompatible Polymer Laboratory of the Department of Science and Molecular and Biomolecular Technology (STEMBIO) of the University of Palermo. It consists of electrospun fibers based on synthetic polymers. Electrospinning is a technique that uses a high voltage source for biasing a polymer solution or a polymer melt, which is then accelerated toward an opposite polarity collector. Through electrospinning, one can obtain the 3-dimensional scaffold composed of micronanometer polymeric fibers, interconnected to form a microporous structure $[27,28]$. $\alpha, \beta$-Poly $(N$-2-hydroxyethyl$\mathrm{D}, \mathrm{L}$ )-aspartamide (PHEA) is the starting polymer; we used it for the production of copolymers for our scaffold. PHEA is a biocompatible synthetic polymer, soluble in water, with a similar structure to human amino acids. The use of PHEA as carriers of drugs and as a starting material for many other biomedical and pharmaceutical applications has already been reported [29,30]. PHEA was linked with polylactic acid (PLA) and subsequently electrospun in a mixture with polycaprolactone (PCL) [31,32]. Scaffolds obtained from the PHEA-PLA/PCL mixture had fibers with diameters from $500 \mathrm{~nm}$ to $1 \mu \mathrm{m}$, similar to the ECM. In fact, the adhesion, proliferation and differentiation of cells are strongly influenced by size, geometry, and density of the pores and the surface properties [33-40]. From a study carried out previously by our group, PHEA-PLA/PCL was found to be a biocompatible material, elastic, and possessing great mechanical strength [41].
The data obtained from in vivo experiments showed that the material has good biocompatibility, evoking an inflammatory response of modest degree, which has a prime role in the reabsorption of the material and processes of tissue regeneration. Subsequently, the scaffold was made tubular in a structure with a diameter of $\sim 5 \mathrm{~mm}$ and a length of a few centimeters. The material was also bound to heparin by covalent bonding to reduce the risk of thrombosis [42].

We performed an arteriovenous fistula (AFV) between the external left iliac artery and the external left iliac vein in a 4-month-old pig model weighing $40 \mathrm{~kg}$. Our experiments were conducted according to the provisions of Legislative Decree no 26 of March 4, 2014, implementing Directive 2010/63/EU on the protection of animals used for scientific purposes, after regulatory approval of the project by the Italian Ministry of Health. All animal experiments were in compliance with the Animal Research: Reporting of In Vivo Experiments guidelines and were carried out in accordance with the EU Directive 2010/63/EU guidelines for animal experiments, the National Institutes of Health guide for the care and use of laboratory animals (legislative decree no 26, March 4, 2014) and the Organismo Preposto al Benessere Animale of the "A. Mirri” Zooprophylactic Institute.

The anesthetic protocol included premedication $(6.3 \mathrm{mg} / \mathrm{kg}$ zolazepam tiletamine $+2.3 \mathrm{mg} / \mathrm{kg}$ xylazine $)$, induction $(0.5 \mathrm{mg} / \mathrm{kg}$ propofol), and maintenance (isoflurane + pancuronium, $12: 7 \mathrm{mg} / \mathrm{kg}$ ). After obtaining access to "J" in the left iliac fossa, we proceeded to the isolation of the iliac vessels and packaging of secondary arteriovenous fistula between the left external iliac artery and the vein ipsilateral homologous, with lateroterminal anastomosis on the arterial side and terminolateral anastomosis on the venous side; this was carried out by means of double hemicontinuous suture of $180^{\circ}$ with the use of a suture thread of a nonabsorbable Prolene type 8-0 (Fig 1). At the moment of the arterial unclamping, we were able, macroscopically, to appreciate a good pulse rate on the prosthetic surface. After surgery, the animal was subjected to a liquid diet for the first 24 hours and antibiotic treatment with the use of oxytetracycline $(20 \mathrm{mg} / \mathrm{kg} / \mathrm{d}$ for 3 days). The flow within the AFV was assessed by means of Doppler ultrasound examination with the use of a microconvex probe of 4-7.5 MHz. The study of the flow was performed by means of Doppler ultrasound every week. In the 1st 2 weeks, the Doppler checks revealed the patency of our AFV (Fig 2). After 1 month, seeing the Doppler scaffold thrombosis responses, we proceeded to en bloc scaffold removal for histopathologic examination. The histologic sections of the surgical specimen were analyzed, after fixing in a $10 \%$ formalin solution, with the use of hematoxylin-eosin staining.

\section{RESULTS}

The bioresorbable tubular prosthesis proved to be easy to handle and resistant to traction during the anastomoses. The anastomosis proved to be leak proof, but subject to an arterial pressure regime, as evidenced by the absence of signs of intraoperative bleeding and early complications.

The scaffold developed by the STEMBIO laboratory also seemed to accord with the suture needle passage, making it, from a surgical point of view, particularly suited to clinical applications. After this procedure, the scaffold remained perfectly intact and impermeable to blood serum. The scaffold showed great flexibility, allowing it to pulsate in the same manner as the adjacent arteries. Doppler examination 


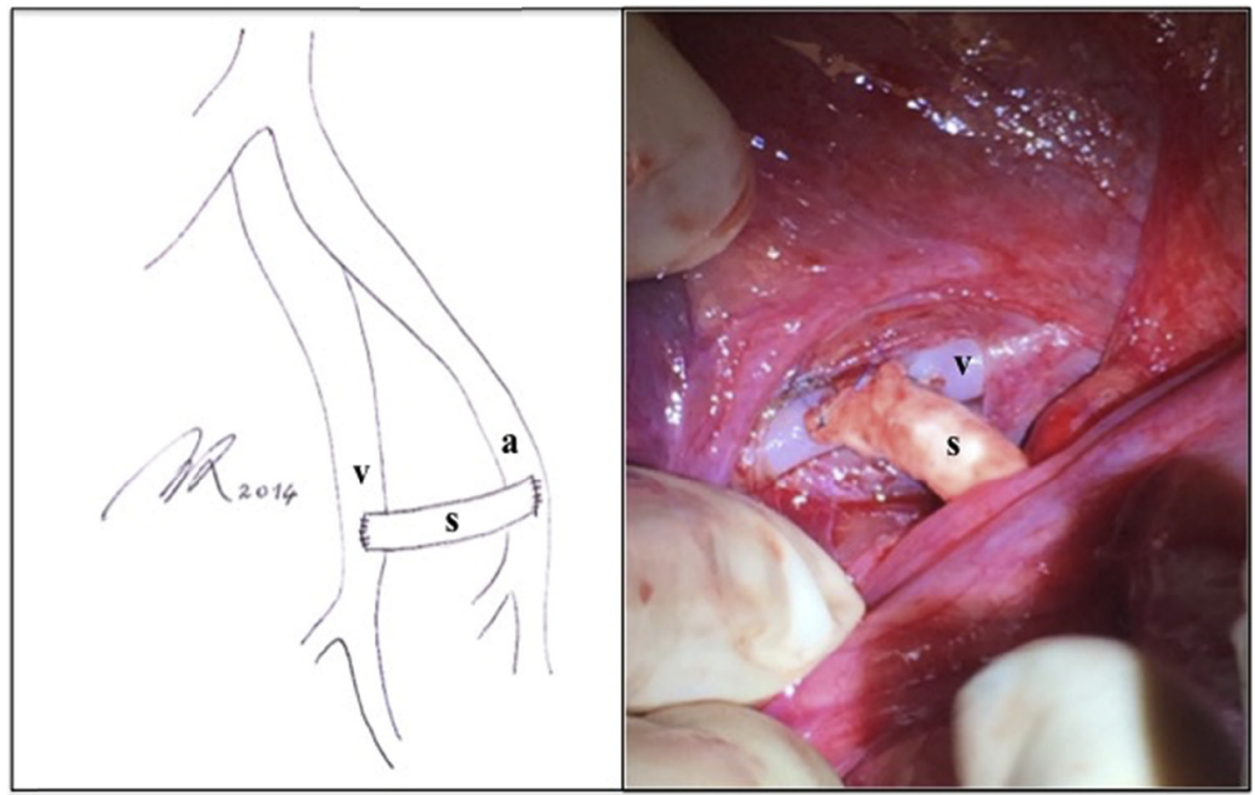

Fig 1. Bridge fistula (s) between the left external iliac artery (a) and the ipsilateral homologous vein (v).

performed immediately after surgery showed the patency of the anastomosis, with a typically turbulent flow (Fig 2). Subsequent ultrasound evaluations revealed the patency of the graft in the 1st 2 weeks and a thrombosis during the Doppler control in the 3rd week.

Histologic examination showed a chronic granulomatous "foreign body" inflammation with giant cells; this was associated with a fibrotic stromal reaction and multiple small newly formed vessels. It was possible to still see the presence of as yet unabsorbed material in the context of granulomatous inflammation (Fig 3).

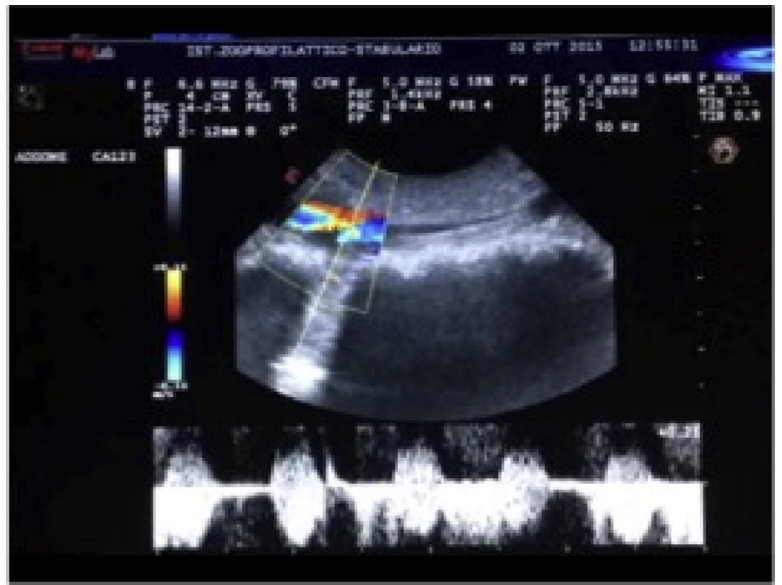

Fig 2. Doppler ultrasound performed immediately after surgery, showing the patency of the anastomosis, with a typically turbulent flow.

\section{DISCUSSION}

The goal of tissue engineering is to obtain a biofunctional and bioabsorbable scaffold, capable of fostering the regeneration of native tissue $[43,44]$. The possibility of producing bioengineered vessels is the subject of several experimental studies [45-66]; however, the material to be proposed as a "scaffold ideal" has not yet been found [35-40,67-80]. The scaffold created in the STEMBIO laboratories proved to be biocompatible, as evidenced by our preliminary studies in the mouse model and as confirmed by the present experiment with the use of the pig model. Our scaffold differs from others used so far, because it seems to present the structural characteristics that make it suitable for the

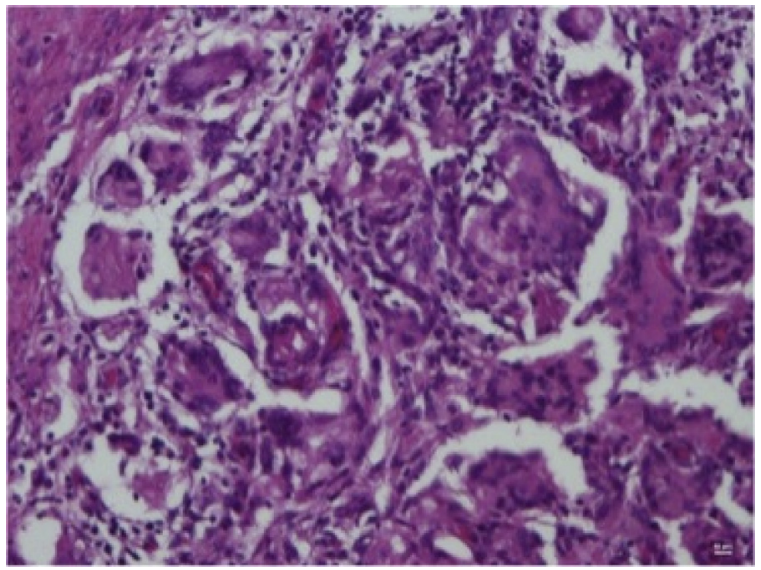

Fig 3. Chronic granulomatous "foreign body" inflammation with giant cells, associated with a fibrotic stromal reaction and multiple small newly formed vessels. 
temporary replacement of blood vessels, without being affected by the early hydrolysis phenomena which too quickly degrade the other materials proposed so far. The histologic results highlighted how the time required for the degradation of our scaffold is $>1$ month. However, we were able to observe the start of a regeneration process, as evidenced by the presence of neovascularization with the formation of an intricate vascular network associated with characteristic cellular elements of chronic inflammation.

The electrospinning of PHEA-PLA in a mixture with PCL resulted in a scaffold with excellent elasticity, probably related to the regularity and dimensional uniformity of the fibers and the absence of a merger between them; these morphologic characteristics are similar to those of the native ECM. In addition, our vascular substitute showed good mechanical properties, allowing easy handling during the experiments conducted. After the AVF had been created, arterial unclamping showed that the graft presented good compliance, responding to changes in blood flow and arterial pulse waves. The tensile properties and the microporous structure are responsible for 2 other fundamental results of our research: the complete absence of bleeding or serous leakage through the walls, and excellent resistance to the needle suture passage, with a consequent perfect seal of the anastomosis. The ultrastructure of the scaffold, with an intricate plot of nanofilaments distributed over a thickness of $\sim 0.5 \mathrm{~mm}$, enables the cells to colonize the scaffold and, at the same time, prevents fluid from exuding from the surface. It is these same characteristics that guarantee that this tissue remains intact during the needle passage from the suture, because the fibers are spread apart and are not in any way damaged or severed by the mechanical puncture. This resistance to tension guarantees the perfect seal of the anastomosis, avoiding blood loss at the point of suture. This characteristic resistance to puncture may, prospectively, allow the use of such devices for vascular access use, and, in particular, for the performing bridge fistulas.

Polymer thrombogenicity was partially resolved by functionalizing it with heparin molecules covalently bonded to the nanostructure of the scaffold. Although the scaffold was pervious only for a month, we had no evidence of early thrombosis phenomena, despite the complete absence of anticoagulant therapy. Heparin also had an important role in guiding vascular endothelialization and by stimulating numerous growth factors $[42,81]$. This would allow the circulating stem cells to engraft to the implanted tissue and promote the regeneration of a fabric (regarding mechanical and biologic characteristics) similar to that of the host organism. Three weeks after implantation, the graft showed thrombosis phenomena; we think that one of the major causes of thrombosis may have been an inappropriate postoperative anticoagulant regimen. Probably, the absence of flow within the vascular graft did not allow effective colonization, particularly in its central portion, an event that contributed to only partial resorption of the material, especially in the part farthest from the anastomosis area.

\section{CONCLUSION}

The "ideal scaffold" boasts certain fundamental properties: It must be made from biocompatible material, having a degradation rate that corresponds to the production of new ECM by the host; and it must possess the ability to interact with host cells, mechanical properties, and ultrastructural characteristics that match the target anatomic site.

The biocompatibility of PHEA-PLA/PCL and its physical properties make it suitable in the replacement of vessels. The main disadvantage is that its thrombogenicity is only partially solved by adding heparin to the scaffold. To resolve this issue and obtain a new vessel from a synthetic substitute, we will need to conduct further studies in which individualized anticoagulation treatments will be used; these will be associated with the use of PHEA-PLA/PCL scaffolds that could be further functionalized with growth factors to modulate the inflammatory response and coagulation.

\section{REFERENCES}

[1] Fox CJ, Gillespie DL, O'Donnell SD, Rasmussen TE, Goff JM, Johnson CA, et al. Contemporary management of wartime vascular trauma. J Vasc Surg 2005;41:638-44.

[2] Tsai JW, Ayubi FS, Rice RD, Zhang Z, Armstrong PJ. Permacol (porcine dermal collagen) and Alloderm (acellular cadaveric dermis) as a vascular patch repair for common carotid arteriotomy in a rabbit model. Ann Vasc Surg 2009;23:374-81.

[3] Muto A, Nishibe T, Dardik H, Dardik A. Patches for carotid artery endarterectomy: current materials and prospects. J Vasc Surg 2009;50:206-13.

[4] Tremblay D, Zigras T, Cartier R, Leduc L, Butany J, Mongrain R, et al. A comparison of mechanical properties of materials used in aortic arch reconstruction. Ann Thorac Surg 2009;88: 1484-91.

[5] Smaill BH, McGiffin DC, Legrice IJ, Young AA, Hunter PJ, Galbraith AJ. The effect of synthetic patch repair of coarctation on regional deformation of the aortic wall. J Thorac Cardiovasc Surg 2000;120:1053-63.

[6] Hertzer NR, Mascha EJ. J Vasc Surg 2006;43:959-68.

[7] Jacobowitz GR, Kalish JA, Lee AM, Adelman MA, Riles TS, Landis R. Long-term follow-up of saphenous vein, internal jugular vein, and knitted Dacron patches for carotid artery endarterectomy. Ann Vasc Surg 2001;15:281-7.

[8] Aburahma AF. Patch closure improves results with carotid endarterectomy. Semin Vasc Surg 2004;17:243-52.

[9] Wong P, Hopkins S, Vincente D, Williams K, Macri N, Berguer R. Differences in neointima formation between impervious and porous polytetrafluoroethylene vascular patch material. Ann Vasc Surg 2002;16:407-12.

[10] Bond R, Rerkasem K, Naylor R, Rothwell PM. Patches of different types for carotid patch angioplasty. Cochrane Database Syst Rev 2004;(2):CD000071.

[11] Edelman ER. Vascular tissue engineering: designer arteries. Circ Res 1999;85:1115-7.

[12] Christine ES, Jennie MB. Acellular vascular tissues: natural biomaterials for tissue repair and tissue engineering. Biomaterials 2000;21:2215-31.

[13] l'Heureux N, Dusserre N, Marini A, Garrido S, de la Fuente L, McAllister T. Technology insight: the evolution of tissue-engineered vascular grafts-from research to clinical practice. Nat Clin Pract Cardiovasc Med 2007;4:389-95.

[14] Choi JS, Kim EY, Kim MJ, Giegengack M, Khang FA, Khang $G$, et al. In vitro evaluation of the interactions between human corneal endothelial cells and extracellular matrix proteins. Biomed Mater 2013;8:014108. 
[15] Shin'oka T, Matsumura G, Hibino N, Naito Y, Watanabe M, Konuma T, et al. Midterm clinical result of tissueengineered vascular autografts seeded with autologous bone marrow cells. J Thorac Cardiovasc Surg 2005;129:1330-8.

[16] Daar AS. Regenerative medicine: a taxonomy for addressing ethical, legal and social issues. In: Gutmann T, Daar AS, Sells RA, Land W, editors. Ethical, legal, and social issues in organ transplantation. Munich: Pabst; 2005. p. 368-77.

[17] Buttery L, Shakesheff KM. A brief introduction to different cell types. In: Polak J, Mantalaris S, Harding SE, editors. Advances in tissue engineering. London: Imperial College Press; 2008. p. 16-32.

[18] Xynos ID, Hukkanan MVJ, Batten J, Buttery LD, Hench LL, Polak JM. Calcif Tissue Int 2000;67:321-9.

[19] Evans MJ, Kaufman MH. Nature 1981;292:154-6.

[20] Thomson JA, Itskovitz-Eldor J, Shapiro SS, Waknitz MA, Swiergiel JJ, Marshall VS, et al. Science 1998;282:1145-7.

[21] Guillot PV, Cui W, Fisk NM, Polak J. Cell J Mol Med 2007:11:935-44.

[22] Polak DJ. J R Soc Interface 2010;7:S777-81.

[23] Takahashi K, Yamanaka S. Cell 2006;126:663-76.

[24] Zhanga X, Reagan MR, Kaplan DL. Adv Deliv Rev 2009;61:988-1006.

[25] Singh M, Tech B, Berkland C, Detamore MS. Tissue Eng 2008;14:4.

[26] Day RM, Boccaccini AR, Maquet V, Shurey S, Forbes A, Gabe SM, et al. J Mater Sci Mater Med 2004;15:729-34.

[27] Rim NG, Shin CS, Shin H. Current approaches to electrospun nanofibers for tissue engineering. Biomed Mater 2013:8:014102.

[28] Xu W, Atala A, Yoo JJ, Lee SJ. Controllable dual protein delivery through electrospun fibrous scaffolds with different hydrophilicities. Biomed Mater 2013;8:014104.

[29] Craparo EF, Teresi G, Bondì ML, Licciardi M, Cavallaro G. Int J Pharm 2011;406:135-44.

[30] Licciardi M, Cavallaro G, di Stefano M, Fiorica C, Giammona G. Macromol Biosci 2011;11:445-54.

[31] Pitarresi G, Palumbo FS, Fiorica C, Calascibetta F, Giammona G. European Polym J 2010;46:181-4

[32] Pitarresi G, Palumbo FS, Albanese A, Licciardi M, Calascibetta F, Giammona G. Eur Polym J 2008:44:3764-75.

[33] Choi SW, Zhang Y, Xia Y. Langmuir 2010;26:19001-6.

[34] Leong KF, Chua CK, Sudarmadji N, Yeong WY. Engineering functionally graded tissue engineering scaffolds. J Mech Behav Biomed Mater 2008;1:140-52.

[35] Annabi N, Nichol JW, Zhong X, Ji C, Koshy S, Khademhosseini A, et al. Controlling the porosity and microarchitecture of hydrogels for tissue engineering. Tissue Eng Part B Rev 2010;16:371-83.

[36] Owen SC, Shoichet MS. Design of three-dimensional biomimetic scaffolds. J Biomed Mater Res A 2010;94A:1321-31.

[37] Oh SH, Park IK, Kim JM, Lee JH. In vitro and in vivo characteristics of PCL scaffolds with pore size gradient fabricated by a centrifugation method. Biomaterials 2007;28:1664-71.

[38] O'Brien FJ, Harley BA, Yannas IV, Gibson LJ. The effect of pore size on cell adhesion in collagen-GAG scaffolds. Biomaterials 2005;26:433-41.

[39] Liu X, Ma PX. Polymeric scaffolds for bone tissue engineering. Ann Biomed Eng 2004;32:477-86.

[40] Choi S-W, Zhang Y, Xia Y. Three-dimensional scaffolds for tissue engineering: the importance of uniformity in pore size and structure. Langmuir 2010;26:19001-6.

[41] lo Monte AI, Licciardi M, Bellavia M, Damiano G, Palumbo VD, Palumbo FS, et al. Biocompatibility and biodegradability of electrospun PHEA-PLA scaffolds: our preliminary experience in a murine animal model. Dig J Nanomater Biostruct 2012: 841-51.

[42] Pitarresi G, Fiorica C, Palumbo FS, Rigogliuso S, Ghersi G, Giammona G. Heparin functionalized polyaspartamide/polyester scaffold for potential blood vessel regeneration. J Biomed Mater Res A 2014;102:1334-41.

[43] Shin'oka T, Imai Y, Ikada Y. Transplantation of a tissueengineered pulmonary artery. N Engl J Med 2001:344:532-3.

[44] Kaihara S, Kim S, Benvenuto M, et al. End-to-end anastomosis between tissue-engineered intestine and native small bowel. Tissue Eng 1999;5:339-46.

[45] Aikawa M, Miyazawa M, Okamoto K, Toshimitsu Y, Torii T, Okada K, et al. A novel treatment for bile duct injury with a tissue-engineered bioabsorbable polymer patch. Surgery 2009;147: $575-80$.

[46] Cho SW, Park HJ, Ryu JH, Kim SH, Kim YH, Choi CY, et al. Vascular patches tissue-engineered with autologous bone marrow-derived cells and decellularized tissue matrices. Biomaterials 2005;26:1915-24.

[47] Schmidt D, Mol A, Neuenschwander S, Breymann C, Gossi $\mathrm{M}$, Zund $\mathrm{G}$, et al. Living patches engineered from human umbilical cord derived fibroblasts and endothelial progenitor cells. Eur J Cardiothorac Surg 2005;27:795-800.

[48] Stock UA, Sakamoto T, Hatsuoka S, Martin DP, Nagashima M, Moran AM, et al. Patch augmentation of the pulmonary artery with bioabsorbable polymers and autologous cell seeding. J Thorac Cardiovasc Surg 2000;120:1158-67.

[49] Yang C, Sodian R, Fu P, Luders C, Lemke T, Du J, et al. In vitro fabrication of a tissue engineered human cardiovascular patch for future use in cardiovascular surgery. Ann Thorac Surg 2006;81:57-63.

[50] Mettler BA, Sales VL, Stucken CL, Anttila V, Mendelson K, Bischoff J, et al. Stem cell-derived, tissue-engineered pulmonary artery augmentation patches in vivo. Ann Thorac Surg 2008:86:132-40.

[51] Sales VL, Mettler BA, Lopez-Ilasaca M, Johnson JA, Mayer JE. Endothelial progenitor and mesenchymal stem cellderived cells persist in tissue-engineered patch in vivo: application of green and red fluorescent protein-expressing retroviral vector. Tissue Eng 2007;13:525-35.

[52] Mendelson K, Aikawa E, Mettler BA, Sales V, Martin D, Mayer JE, et al. Healing and remodeling of bioengineered pulmonary artery patches implanted in sheep. Cardiovasc Pathol $2007 ; 16: 277-82$

[53] Takahashi H, Yokota T, Uchimura E, Miyagawa S, Ota T, Torikai K, et al. Newly developed tissue-engineered material for reconstruction of vascular wall without cell seeding. Ann Thorac Surg 2009;88:1269-76.

[54] Ceonzo K, Gaynor A, Shaffer L, Kojima K, Vacanti CA, Stahl GL. Polyglycolic acid-induced inflammation: role of hydrolysis and resulting complement activation. Tissue Eng 2006;12: $301-8$.

[55] Vindigni V, Cortivo R, Iacobellis L, Abatangelo G, Zavan B. Hyaluronan benzyl ester as a scaffold for tissue engineering. Int J Mol Sci 2009;10:2972-85.

[56] Genasetti A, Vigetti D, Viola M, Karousou E, Moretto P, Rizzi M, et al. Hyaluronan and human endothelial cell behavior. Connect Tissue Res 2008:49:120-3.

[57] Ibrahim S, Ramamurthi A. Hyaluronic acid cues for functional endothelialization of vascular constructs. J Tissue Eng Regen Med 2008;2:22-32.

[58] Turner NJ, Kielty CM, Walker MG, Canfield AE. A novel hyaluronan-based biomaterial (Hyaff-11) as a scaffold for endothelial cells in tissue engineered vascular grafts. Biomaterials 2004;25:5955-64.

[59] Remuzzi A, Mantero S, Colombo M, Morigi M, Binda E, Camozzi D, et al. Vascular smooth muscle cells on hyaluronic acid: Culture and mechanical characterization of an engineered vascular construct. Tissue Eng 2004;10:699-710.

[60] Pasquinelli G, Vinci MC, Gamberini C, Orrico C, Foroni L, Guarnieri C, et al. Architectural organization and functional features ofearly endothelial progenitor cells cultured in a hyaluronanbased polymer scaffold. Tissue Eng Part A 2009;15:2751-62. 
[61] Lepidi S, Grego F, Vindigni V, Zavan B, Tonello C, Deriu GP, et al. Hyaluronan biodegradable scaffold for smallcaliber artery grafting: preliminary results in an animal model. Eur J Vasc Endovasc Surg 2006;32:411-7.

[62] Pandis L, Zavan B, Abatangelo G, Lepidi S, Cortivo R, Vindigni V. Hyaluronan-based scaffold for in vivo regeneration of the rat vena cava: preliminary results in an animal model. J Biomed Mater Res 2010;93:1289-96.

[63] Zavan B, Vindigni V, Lepidi S, Iacopetti I, Avruscio G, Abatangelo $G$, et al. Neoarteries grown in vivo using a tissueengineered hyaluronan-based scaffold. FASEB J 2008;22:2853-61.

[64] Lepidi S, Abatangelo G, Vindigni V, Deriu GP, Zavan B, Tonello C, et al. In vivo regeneration of small-diameter $(2 \mathrm{~mm})$ arteries using a polymer scaffold. FASEB J 2006;20:103-5.

[65] Patel A, Fine B, Sandig M, Mequanint K. Elastin biosynthesis: the missing link in tissue-engineered blood vessels. Cardiovasc Res 2006;71:40-9.

[66] Karnik SK, Brooke BS, Antonio BG, Sorensen L, Wythe JD, Schwartz RS. A critical role for elastin signaling in vascular morphogenesis and disease. Development 2003;130: 411-23.

[67] Sill TJ, von Recum HA. Electrospinning: applications in drug delivery and tissue engineering. Biomaterials 2008;29: 1989-2006.

[68] Lutolf MP, Lauer-Fields JL, Schmoekel HG, Metters AT, Weber FE, Fields GB, et al. Synthetic matrix metalloproteinasesensitive hydrogels for the conduction of tissue regeneration: engineering cell-invasion characteristics. Proc Natl Acad Sci U S A 2003;100:5413-8.

[69] Bahney CS, Hsu C-W, Yoo JU, West JL, Johnstone B. A bio-responsive hydrogel tuned to chondrogenesis of human mesenchymal stem cells. FASEB J 2011.

[70] Tibbitt MW, Anseth KS. Hydrogels as extracellular matrix mimics for 3D cell culture. Biotechnol Bioeng 2009;103:655-63.
[71] Nicodemus GD, Bryant SJ. Cell encapsulation in biodegradable hydrogels for tissue engineering applications. Tissue Eng Part B Rev 2008;14:149-65.

[72] Chan B, Leong K. Scaffolding in tissue engineering: General approaches and tissue-specific considerations. Eur Spine J 2008;17: 467-9.

[73] Liu X, Won Y, Ma PX. Porogen-induced surface modification of nano-fibrous poly(l-lactic acid) scaffolds for tissue engineering. Biomaterials 2006;27:3980-7.

[74] Petrie TA, Raynor JE, Dumbauld DW, Lee TT, Jagtap S, Templeman KL, et al. Multivalent integrin-specific ligands enhance tissue healing and biomaterial integration. Sci Transl Med 2010;2:45ra60.

[75] Shekaran A, García AJ. Extracellular matrixmimetic adhesive biomaterials for bone repair. J Biomed Mater Res A 2011;96A:261-72.

[76] Takagi J. Structural basis for ligand recognition by RGD (Arg-Gly-Asp)-dependent integrins. Biochem Soc Trans 2004;32(Pt 3):403-6.

[77] Geckil H, Xu F, Zhang X, Moon S, Demirci U. Engineering hydrogels as extracellular matrix mimics. Nanomedicine 2010;5: 469-84.

[78] Raub CB, Unruh J, Suresh V, Krasieva T, Lindmo T, Gratton E, et al. Image correlation spectroscopy of multiphoton images correlates with collagen mechanical properties. Biophys J 2008;94:2361-73.

[79] Wei G, Ma PX. Structure and properties of nanohydroxyapatite/polymer composite scaffolds for bone tissue engineering. Biomaterials 2004;25:4749-57.

[80] Helm CL, Zisch A, Swartz MA. Engineered blood and lymphatic capillaries in 3-D VEGF-fibrin-collagen matrices with interstitial flow. Biotechnol Bioeng 2007:96:167-76.

[81] Xu D, Fuster MM, Lawrence R, Esko JD. Heparan sulphate regulates VEGF 165- and VEGF 121-mediated vascular hyperpermiability. J Biol Chem 2011;286:737-45. 